\section{MRS seeks award nominations for 2014}

Deadline: October 1, 2013

\section{Mid-Career Researcher Award www.mrs.org/mra}

The Materials Research Society (MRS) is now accepting nominations for the Mid-Career Researcher Award to be presented at the 2014 MRS Spring Meeting in San Francisco, Calif.

The annual award recognizes exceptional achievements in materials research made by mid-career professionals. It is intended to honor an individual

\section{MRS} who is between the ages of 40 and 52 at the time of nomination. Exceptions may be made for an interruption in career progression due to family or military service. The award recipient must also demonstrate notable leadership in the materials area.

The award consists of a $\$ 5,000$ cash prize, a presentation trophy, and a certificate. Meeting registration fee, transportation, and hotel expenses to attend the MRS Spring Meeting at which the award is presented will be reimbursed.

The Mid-Career Researcher Award is made possible through an endowment established by Aldrich Materials Science.

\section{Outstanding Young Investigator Award www.mrs.org/oyi}

The Materials Research Society is accepting nominations for the Outstanding Young Investigator (OYI) Award to be presented at the 2014 MRS Spring Meeting in San Francisco.
The OYI Award recognizes outstanding interdisciplinary scientific work in materials research by a scientist or engineer under the age of 36 (as of January 1,2014). The award recipient must show exceptional promise as a developing leader in the materials area.

The award consists of a $\$ 5,000$ prize, a presentation trophy, and a citation certificate. Reasonable travel expenses to attend the MRS Meeting at which the award is presented and the meeting registration fee will be reimbursed.

\section{Innovation in Materials Characterization Award www.mrs.org/IMCA}

The Materials Research Society is accepting nominations for the Innovation in Materials Characterization Award to be presented at the 2014 MRS Spring Meeting in San Francisco, where the recipient is invited to speak at the Awards Ceremony.

The award recognizes an outstanding advance in materials characterization that notably increases the knowledge of the structure, composition, in situ behavior under outside stimulus, electronic, mechanical, or chemical behavior, or other characterization feature of materials. It is not limited to the method of characterization or the class of material observed.

The annual award consists of a $\$ 5,000$ cash prize, a presentation trophy, and a certificate. Meeting registration fee, transportation, and hotel expenses to attend the MRS Meeting at which the award is presented will be reimbursed.

The Innovation in Materials Characterization Award has been endowed by Toh-Ming Lu and Gwo-Ching Wang.

\section{Materials Research Society Fellows www.mrs.org/fellows}

The Materials Research Society seeks to recognize as "MRS Fellow" outstanding members who are notable for their sustained and distinguished contributions to the advancement of materials research. It is intended that - representing excellence in science and engineering, and dedication to the advancement of materials research - the MRS Fellows will collectively exemplify the highest ideals of accomplishment and service embodied in the MRS Mission.

Nomination is open to any MRS member in good standing, whose membership has been continuous for at least five years preceding receipt of the nomination. MRS Fellow is a lifetime appointment.

The deadline for submission of all nominations is October 1, 2013. For guidelines and application forms, access the MRS website at www.mrs.org/ awards or contact Lorri Smiley, Materials Research Society, 506 Keystone Drive, Warrendale, PA 15086-7573, USA; email awardsprogram@mrs.org.

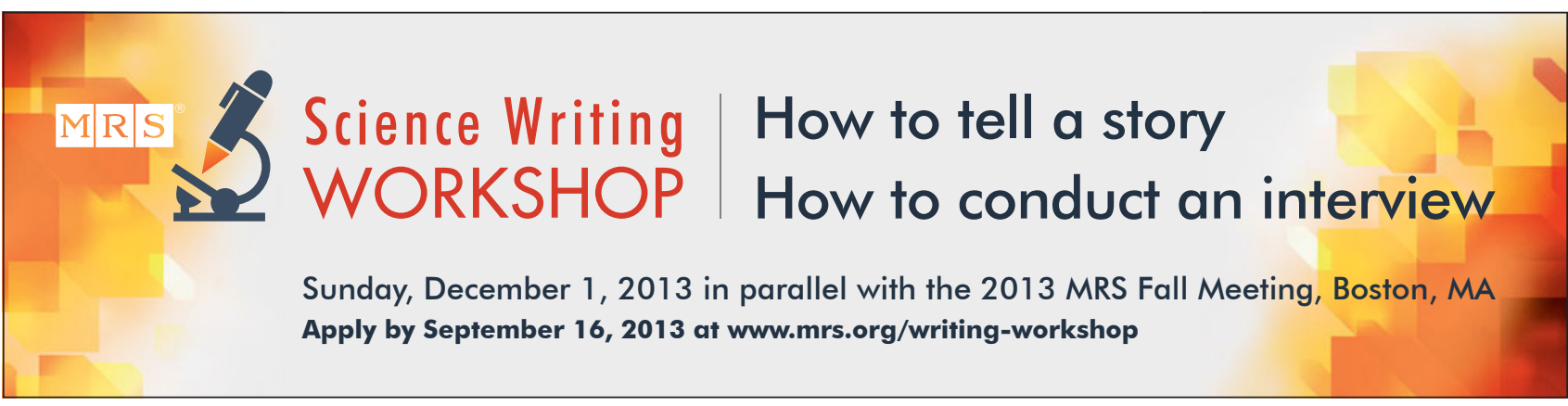

